\title{
What Do We Know about Sensitive Periods in Human Development and How Do We Know It?
}

\author{
Nathan A. Fox \\ University of Maryland, College Park, Md., USA
}

For many years, developmental psychologists have argued for the importance of early experiences with regard to subsequent adaptive behavioral development. Along with this argument has been the corollary that there are critical or sensitive periods during which certain types of experiences must happen for typical development to occur. But a quick inspection of the evidence for both the importance of early experience and the nature of sensitive periods would suggest that most of the data supporting these two tenets are from animal or rodent studies. That is not to say that the research literature on human infants and children is devoid of studies of the effects of negative experiences such as stress, poverty, and maltreatment. These studies abound. But as a discipline, and because of clear ethical considerations, we must rely on research that is correlational in design to understand early experience and sensitiveperiod effects. These studies on the effects of adverse experience are compelling but even more so are the animal and rodent studies where random assignment and experimental manipulation are more easily created with data suggesting that early experience and its timing are of significant importance for typical development. The studies in rodents by Victor Denenberg, Seymour Levine, and, more recently, Paul Plotsky and Michael Meaney are examples of this work, as is the work with nonhuman primates by Harry Harlow and his students. The translation of this work has been more widely accepted recently with the advent of advances in both brain imaging methods and genetic and epigenetic approaches to understanding the underlying neural mechanisms supporting development. But there is still a dearth of experimental evidence with human subjects that can support the animal work.

Of course, there are exceptions, particularly in the areas of sensation and perception. Following up on the animal work of Hubel and Wiesel, who identified the importance of early visual experience for the formation of cortical architecture involved in vision, Daphne Mauer, in a series of studies, demonstrated the importance of this experience and the nature of the timing of experience with infants who had been born with cataracts and who had surgery at different points in the first year of life, thus providing them with patterned visual stimulation at different points in development. There is also a good deal of work on a phenomenon known as perceptual narrowing. Human infants appear capable of discriminating the sounds from languages from

\begin{tabular}{ll}
\hline KARGER & ๑ 2014 S. Karger AG, Basel \\
0018-716X/14/0574-0173\$39.50/0 \\
$\begin{array}{l}\text { E-Mail karger@karger.com } \\
\text { www.karger.com/hde }\end{array}$
\end{tabular}

Nathan A. Fox

Child Development Lab

3304 Benjamin Building

College Park, MD 20742-1131 (USA)

E-Mail fox@umd.edu 
around the world during the first half year of life, as they are also able to discriminate amongst faces from different races - and even amongst different monkey faces. By the end of the first year of life, these discriminative skills have declined. Infants are better able to discriminate sounds, but from their native language; they are better able to discriminate faces of people, but only from their own community; and they are no longer able to discriminate amongst faces of different monkeys. There have been studies to see whether one can lengthen the window across which these skills remain by having the infant hear more than one language or view faces from multiple racial groups. These manipulations seem to work, but only for brief periods of time and only if exposure is maintained.

One conclusion from both the animal and human literatures is that there is evidence for the effects of early experience and for the presence of sensitive periods with regard to perceptual abilities. But what about more complex cognitive or social behaviors: Are there sensitive periods during which input from the environment is more important than at other points in time for IQ, memory or executive function? Is there evidence in the human literature for sensitive periods in social development? The answer is that there is not much in the way of evidence for sensitive periods for either cognitive or social behaviors. This usually is surprising to developmental scientists who, it is fair to say often, operate on the assumption that earlier is better with regard to the timing of experience.

The work my colleagues Charles A. Nelson and Charles H. Zeanah and I have completed in the Bucharest Early Intervention Project has allowed us to address some of these issues. We have studied 136 children abandoned at or soon after birth to institutions in Romania. Half of these children were placed into foster-family care (the range of their ages at time of placement was 5-30 months). Half remained in the institutions where they had been living. We followed the children periodically with assessments of cognitive and social behavior. Here's what we found: Although initially we identified a sensitive period for cognitive development (IQ), this timing effect, present early on, was no longer present when we assessed the children at ages 8 and 12. While there was an effect of the intervention - those placed into families had higher full-scale IQ scores compared to those randomized to remain in the institution - the age of a child's placement did not seem to affect the outcome. This lack of timing effect was also true for measures of executive function, inhibitory control, and error monitoring. On the other hand, timing of placement did matter for social behavior. Children placed before 24 months of age had more secure attachment relationships with their caregivers compared to those placed after age two, and these same children had better social skills (by observation) and were more socially competent (by teacher report) at age eight. As well, the incidence of indiscriminate behavior was significantly lower in those placed before age two.

The evidence from our study suggests that there is a good deal of flexibility and plasticity in the neural systems underlying the emergence of cognition. It does speak to the importance of early experience and also to the continued maintenance of good quality environments over childhood. On the other hand, our data support the idea that there are sensitive periods for social behavior. Earlier appears better, particularly with regard to young children receiving contingent and responsive stimulation as well as warmth and affection. We still know little about the underlying neural mechanisms supporting the development of social behavior, but it is clear that early experience matters. 


\section{References}

Knudsen, E.I. (2004). Sensitive periods in the development of the brain and behavior. Journal of Cognitive Neuroscience, 16, 1412-1425.

Levine, S. (2005). Developmental determinants of sensitivity and resistance to stress. Psychoneuroendocrinology, 30, 939-946.

Maurer, D., Mondloch, C.J., \& Lewis, T.L. (2007). Sleeper effects. Developmental Science, 10, 40-47.

Smyke, A.T., Zeanah, C.H., Fox, N.A., Nelson, C.A., \& Guthrie, D. (2010). Placement in foster care enhances quality of attachment among young institutionalized children. Child Development, 81, 212 223.

Zeanah, C.H., Gunnar, M.R., McCall, R.B., Kreppner, J.M., \& Fox, N.A. (2011). Sensitive periods. In R.B. McCall, M.H. van IJzendoorn, F. Juffer, C.J. Groark, \& V.K. Groza (Eds.), Children without permanent parents: Research, practice, and policy. Monographs of the Society for Research in Child Development, 76, 147-162. 